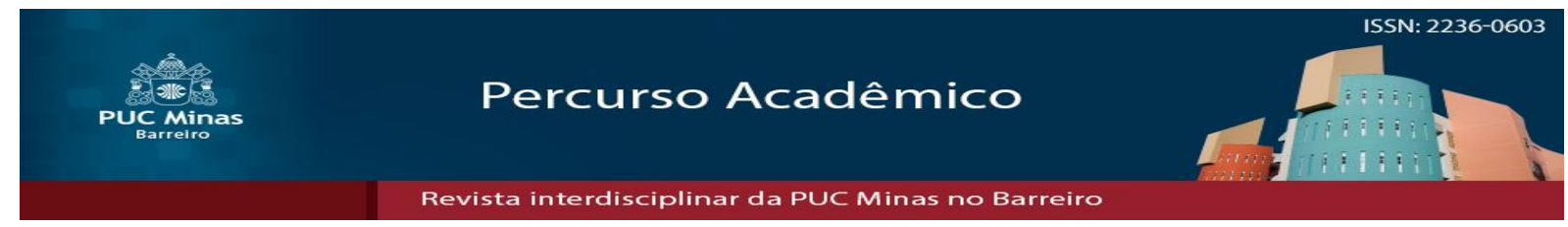

\title{
Uma breve análise da intervenção estatal brasileira à luz do Programa Minha Casa Minha Vida (PMCMV)
}

\author{
A brief analysis of the Brazilian state intervention under the \\ auspices of My House, My Life Program (Programa Minha Casa \\ Minha Vida - PMCMV)
}

\begin{abstract}
Maria José Celestino Medrado ${ }^{1}$
Resumo

Este trabalho realizou uma breve análise bibliográfica e documental sobre a intervenção do estado no atual programa nacional de habitação -"Minha Casa Minha Vida". Para isso, priorizou-se o período de 2009 a 2014, focalizando as ações destinadas a famílias com até três salários mínimos. Foi constatado que o Programa "Minha Casa Minha Vida" apresenta significante valor mercadológico, pois foi implementado em um setor de grande importância para a geração de emprego e renda. No entanto, os resultados alcançados com o programa em relação aos indicadores de avaliação de desempenho, a saber, economicidade, eficiência, eficácia e efetividade, são insatisfatórios, pois não apresentam simetria com o bem-estar social dos beneficiários ou com aspectos ambientais; além de apresentarem disparidade entre os gastos governamentais destinados ao programa. Nesse sentido, o referido programa favoreceu o mercado interno, o setor de construção civil e os aspectos político-partidários. Em contrapartida, favoreceu a exclusão social, deixando à margem indivíduos que apresentam baixo nível socioeconômico, além de inobservar ações voltadas para os aspectos ambientais de conservação e preservação.

Palavras-chave: Política habitacional. Planejamento urbano. Programa de habitação.
\end{abstract}

\begin{abstract}
This work carried out a brief bibliographic and documentary analysis about the Brazilian government housing program "Minha Casa, Minha Vida" (My House, My Life) between 2009 and 2014. It focused on actions to the poor families with income of three minimum wages or less per month. The results from this research showed us that this specific program was able to generate huge economic impacts, once it stimulated the construction sector. However, the achieved results were unsatisfactory. It was because they haven't showed symmetry on this welfare Program towards really need it environmental aspects which surrounded it. Besides, there were disparities on the public spending. On this way, the target program has developed the internal market, the Civil and Building Engineering and the political party interests. However, it allowed social exclusion, leaving individuals with low socio economical status to the margin, as well as it hasn't followed rules towards the environmental aspects related to the conservation and to the preservation of the nature in the community.
\end{abstract}

Keywords: Housing policy. Urban planning. Housing program.

Artigo recebido em 15 de Outubro de 2015 e aprovado em 30 de Março de 2017.

1 Mestranda em Recursos Humanos e Gestão do Conhecimento (Universidad Europea del Atlántico/Bolsista Funiber). Especialista em MBA em Gestão Financeira e Controladoria (Universidade Estácio de Sá). Graduada em Ciências Econômicas (Unisul). Email: economista@mariamedrado.ecn.br. 


\title{
Introdução
}

Este estudo surgiu com o intuito de pesquisar, analisar e legitimar a importância econômica para o desenvolvimento do planejamento urbano e regional, assim como de programas governamentais, a saber, os programas de habitação, que têm como finalidade não só expandir estes serviços para uma parcela da sociedade, mas, sobretudo, beneficiar e disponibilizar maiores recursos para a camada mais necessitada. Legitima esse posicionamento o texto do Ministério das Cidades (BRASIL, 2003), que defende o combate às desigualdades sociais, transformando as cidades em espaços mais humanizados.

Faz-se notável, assim, otimizar o máximo de investimentos direcionados à diminuição da desigualdade social, e à melhoria na distribuição de renda e no aumento da geração de trabalho e renda, visando, dessa forma, um aumento no desenvolvimento e crescimento econômico do país (foco da economia social de mercado presente e característica da atual política governamental no Brasil).

De acordo com o Caderno de Monitoramento do PPA 2012-2015 "Retrato das Políticas Sociais na PNAD 2012":

\begin{abstract}
A Constituição Federal define como objetivos da política de desenvolvimento urbano o ordenamento do pleno desenvolvimento das funções sociais da cidade e a garantia do bem-estar de seus habitantes, tratando a política urbana na perspectiva da gestão democrática e do reconhecimento dos direitos sociais. Sua regulamentação foi instituída pelo Estatuto das Cidades, que preconiza o direito a cidades sustentáveis, entendido como o direito à terra urbana, à moradia, ao saneamento ambiental, à infraestrutura urbana, ao transporte e aos serviços públicos, ao trabalho e ao lazer, para as presentes e futuras gerações, definindo ferramentas e diretrizes para o cumprimento das funções sociais da cidade e da propriedade. Nesse sentido de efetivar a universalização do direito à cidade, destacam-se as políticas de planejamento urbano, acesso à moradia digna, saneamento básico e mobilidade urbana, que além de promover a cidadania, a igualdade de oportunidades e a melhoria da qualidade de vida nas cidades, são determinantes para a desconcentração territorial do crescimento econômico e da geração de empregos. (BRASIL, 2014a, p. 54, grifo nosso).
\end{abstract}

Partindo da necessidade de repensar o planejamento urbano e econômico no Brasil, a pesquisa que se desenvolveu se justifica pela necessidade de analisar a efetividade da intervenção estatal em políticas habitacionais, através da elaboração, implementação e alocação dos seus investimentos em programas habitacionais, em específico, no Programa "Minha Casa, Minha Vida" (PMCMV), relativamente às ações destinadas a famílias com até três salários mínimos, no período de 2009 a 2014. 
A sua importância se origina nos impactos positivos e produtivos para o país, principalmente por sua abrangência territorial, capacidade de estimular a geração de renda e empregos em diversos setores - como da construção civil e o de serviços, coparticipação das três esferas governamentais - federal, estadual e municipal, grande amplitude de beneficiários e no expressivo valor estimado para serem investidos.

A pesquisa também ganha sua legitimidade devido à importância de investigações econômicas sobre os resultados da implementação de programas habitacionais, que foquem o desenvolvimento regional e planejamento urbano, influenciando na diminuição do déficit habitacional e na baixa qualidade de vida das pessoas com renda máxima de três salários mínimos.

Para tal, dividiu-se a apresentação deste artigo em três seções: a primeira seção trata da parte introdutória deste trabalho; a segunda dedica-se à análise bibliográfica e documental sobre a intervenção estatal brasileira através de políticas habitacionais, em especial sobre o programa PMCMV em comparação com programas anteriores; a terceira seção conclui a pesquisa com as considerações finais.

\section{Intervenção estatal brasileira através de políticas habitacionais}

Temos um país bastante rico em recursos naturais. Também possuímos recursos humanos e de capital bastante vantajosos, como o agronegócio e suas inovações tecnológicas. Apesar de tamanha riqueza, vivemos, ainda, com grandes déficits sociais, em especial, a desigualdade de renda e a falta habitacional e de saneamento básico. A estes déficits relacionamos a ausência de cultura de planejamento, ou seja, infelizmente falta em nosso dia a dia o ato de planejar estrategicamente.

Como nos explicita Clementino (2008), o

[...] planejamento [urbano] é fundamental para superar os desafios enfrentados pelas cidades que constituem aglomerações urbanas. É uma forma estruturada de tomar decisões para o desenvolvimento das 'cidades metropolitanas', de acordo com as expectativas da sociedade. O planejamento de áreas metropolitanas constitui espaço privilegiado de negociação entre atores sociais, confrontando e articulando interesses e alternativas para a sociedade. Deve assegurar a ampla mobilização e participação de todos os interessados na discussão, na negociação e na tomada de decisões. Trata-se de alternativa política (e também técnica) de negociação e decisão coletiva, compartilhada sobre o futuro comum dos municípios metropolitanos. Nesse sentido, o ordenamento e o planejamento territorial representam contribuição fundamental para a capacitação e o desenvolvimento sociopolíticos da sociedade desde que seja resultante de um processo de dimensões ao mesmo tempo técnica e política. (CLEMENTINO, 2008, acréscimo nosso). 
Como veremos a seguir o problema de habitação no Brasil é um exemplo histórico de falta de planejamento tanto de cunho urbano, quanto econômico.

\subsection{Intervenção estatal de cunho habitacional: uma breve análise}

No Brasil, conforme Bonduki (1994), a intervenção estatal de cunho habitacional surgiu entre os períodos de 1930 e 1954, durante o governo do presidente Getúlio Vargas. Este período foi caracterizado pela intervenção do Estado "tanto no processo de produção como no mercado de aluguel, abandonando a postura de deixar a questão da construção, comercialização, financiamento e locação habitacional às 'livres forças do mercado', que vigorou até então”. (BONDUKI, 1994, p. 711).

O período Vargas (1930-1954) deu início a uma nova política no país, pois abandonava a ideologia do Estado Liberal da República Velha, que defendia a ideia que o " [...] governo não deve produzir casas para os operários, mas estimular os particulares a investirem [...]" (BONDUKI, 1994, p. 715), para advogar a favor de uma nova ideologia: a que era indispensável a intervenção do governo na produção de moradias populares. (BONDUKI, 1994).

Segundo Bonduki (1994, p. 717),

[...] a formulação pelo Estado de um programa de produção de moradias e de uma política de proteção ao inquilinato tinha ampla aceitação pelas massas populares urbanas e mostrava um governo preocupado com as condições de vida da 'população menos favorecida'.

As ações que visavam à garantia de melhores condições de vida para a população menos favorecida deram originem à imagem do presidente Getúlio Vargas como o pai dos pobres. (BONDUKI, 1994).

Dessa forma, sobre as políticas públicas de cunho habitacional, foco deste trabalho, é possível afirmar que sua origem se deu no governo de Getúlio Vargas, pois a partir de então o Estado se conscientizou que "[...] a questão da habitação dos trabalhadores não se enfrenta através do livre jogo do mercado, mas que é indispensável a intervenção do Estado”. (BONDUKI, 1994, p. 718, grifo nosso).

Devido a essa preocupação em sanar o problema social de habitação no país, são criadas políticas habitacionais, como o Programa "Vila Viva", que têm como principais objetivos 
[...] a redução de parcela do déficit habitacional, a melhoria e recuperação de um estoque de moradias já existentes por meio da reestruturação física e ambiental dos assentamentos, o desenvolvimento social e econômico e a melhoria das condições de vida da população [...] (PIMENTA et al., 2009, p. 4, grifo nosso).

Salienta-se que

O modelo de urbanização brasileiro foi marcado pela desigualdade social e territorial, pelo crescimento desordenado das cidades, pela ociosidade do uso do solo de áreas urbanizadas, pela degradação ambiental e pela priorização do uso do automóvel em detrimento do transporte coletivo. Este modelo é consequência, entre outros motivos, de um planejamento urbano excessivamente normativo e muitas vezes desconectado dos processos reais de produção e transformação das cidades. Também é resultado de políticas públicas urbanas que ignoraram as desigualdades sociais, reforçando a fragmentação da cidade em áreas ricas, onde os investimentos em desenvolvimento urbano sempre foram concentrados, e áreas pobres, desprovidas de investimentos em desenvolvimento urbano e submetidas a uma regulação urbanística muitas vezes excludente. (BRASIL, 2015, p. 145, grifo nosso).

É grande a importância de intervenção estatal para solucionar o problema de moradias precárias em municípios brasileiros, em especial, os que resultam na criação e expansão das favelas. (TONUCCI FILHO; ÁVILA, 2008; DUARTE et al., 2009; GOMES, 2009; PIMENTA et al., 2009). Dessa forma, pode-se supor que o problema de moradia e, consequentemente, o déficit de moradia no país é um problema visível, antigo e bastante crítico em termos econômicos e urbanos.

Segundo a Mensagem Presidencial do Plano Plurianual 2016-2019,

Uma das expressões da carência de moradia é o déficit habitacional, referente à necessidade de novas moradias por constatação de domicílios improvisados ou rústicos, de coabitação familiar, de comprometimento excessivo da renda com aluguel e de adensamento excessivo nos domicílios. Em 2012, o déficit habitacional estimado correspondia a 5,43 milhões de domicílios, dos quais $85,9 \%$ estavam localizados nas áreas urbanas. Em termos relativos, o déficit correspondia a $8,5 \%$ do total de domicílios. Do total do déficit habitacional em 2012, 38,8\% localizavam-se na região Sudeste e $32,7 \%$ na região Nordeste. A carência habitacional também guarda estreita relação com o custo da moradia e com a distribuição de renda da população, verificando-se sua concentração na faixa de renda de até três salários mínimos $(82,5 \%)$ e entre três a cinco salários mínimos $(10,1 \%)$, faixas que somam juntas $92,6 \%$ do déficit. (BRASIL, 2015, p. 140, grifo nosso).

Vale ressaltar que a valorização do espaço urbano é consequência da sua apropriação e seu uso, o que contribui diretamente para a formação de renda que circula no setor imobiliário, uma vez que neste caso o espaço urbano é visto como mercadoria, através da atração de capital privado e público. (DUARTE et al., 2009). Neste âmbito, observa-se a mudança na política pública, na qual o Estado passa de administrador para 
fornecedor de subsídios, concessões, materiais e infraestrutura.

Sendo assim, as intervenções públicas de cunho habitacional, que visam melhorar as condições de vida dos moradores de determinadas regiões urbanas, devem ser analisadas de perto com intuito de verificar se realmente atendem às necessidades básicas da parte envolvida diretamente com as obras do programa, neste caso, os moradores de periferias, vilas e favelas; ou se, simplesmente, atendem ao interesse do setor da construção civil e de grupos político-econômicos.

A seguir, apresentamos uma breve análise de três modelos de intervenção estatal brasileira através de políticas habitacionais, a saber, o Banco Nacional de Habitação (BNH), Programa "Vila Viva" e o Programa "Minha Casa Minha Vida" (PMCMV).

\subsubsection{Modelo de plano nacional de habitação: Banco Nacional de Habitação (BNH)}

Entre as décadas de 1930 e 1964 foram desenvolvidas políticas habitacionais que visavam sanar os problemas oriundos do déficit habitacional e de moradias precárias, promovendo melhoria das condições de vida da população. Dentre elas, tivemos a Fundação da Casa Popular (FCP) criada no governo do presidente Eurico Gaspar Dutra, em $1^{\circ}$ de maio de 1946, destinada "a proporcionar a brasileiros ou estrangeiros com mais de dez anos de residência no país ou com filhos brasileiros a aquisição ou construção de moradia própria, em zona urbana ou rural”. (BRASIL, 1946). Durante seu período de vigência, entre 1946-1964, “estima-se em 120 mil o total de unidades providas pela FCP [...]”. (VALADARES, 2017).

Ainda de acordo com Valadares (2017),

[...] a FCP tinha como principais finalidades: a) proporcionar a aquisição ou construção de moradia própria, na zona urbana ou rural, a brasileiros e a estrangeiros com mais de dez anos de residência no país; b) financiar obras de abastecimento d'água, esgotos, energia elétrica e outras que visassem à melhoria do bem-estar das camadas trabalhadoras; c) proceder a estudos que levassem a processos de barateamento da construção habitacional; d) financiar indústrias de materiais de construção.

Citamos a criação da FCP (1946-1964) por ter tido importância nacional no desenvolvimento urbano dos municípios no período de sua vigência e, também, por ser antecessora do Banco Nacional de Habitação (BNH), modelo que dissertaremos a seguir. 
O BNH (1964-1986) foi criado

[...] em 1964, [...] [quando] a questão da habitação mudou de feição e tomou novo impulso, com o presidente Castelo Branco fazendo do plano habitacional o primeiro grande plano de seu governo. [...] Criado o BNH, este se propôs o seguinte: a) coordenação da política habitacional e do financiamento para o saneamento; b) difusão da propriedade residencial, especialmente para as classes menos favorecidas; c) melhoria do padrão habitacional e eliminação das favelas; d) redução do preço da habitação; e) melhoria sanitária da população; f) estímulo à poupança privada e, conseqüentemente [sic], ao investimento; g) aumento de investimentos nas indústrias de construção civil, de material de construção e de bens de consumo duráveis; h) aumento da oferta de emprego, visando a absorver mão-de-obra ociosa não especializada; i) criação de pólos $[$ sic $] \mathrm{de}$ desenvolvimento com a conseqüente $[$ sic $]$ melhoria das condições de vida nas áreas rurais. (VALADARES, 2017, acréscimo nosso).

A criação do BNH foi um marco nas políticas públicas de cunho habitacional. Seu maior diferencial consistia em ser uma instituição bancária, e não apenas um programa governamental, e, também, uma articulação entre os setores público e privado.

Segundo Valadares (2017),

O modelo proposto pelo BNH representou uma grande inovação em termos de política habitacional. Em primeiro lugar, esta passou a ser comandada por um banco, ao contrário das 'soluções' anteriores baseadas na FCP, caixas de pecúlio e órgãos previdenciários. Segundo, os financiamentos concedidos provinham de um mecanismo de compensação inflacionária - a correção monetária - que reajustava automaticamente os débitos e prestações por índices correspondentes às taxas de inflação, enquanto as 'soluções' precedentes eram implementadas na base de um sistema de subsídio habitacional. E, finalmente, o modelo articulou o setor público com o setor privado, ficando este encarregado, em última análise, da produção, distribuição e controle das habitações. Como salienta G. Bolaffi: 'desde a sua constituição, a orientação que inspirou todas as operações do BNH foi a de transmitir todas as suas funções para a iniciativa privada. $\mathrm{O}$ banco limita-se a arrecadar recursos financeiros para em seguida transferi-los a uma variedade de agentes privados intermediários'.

No período de sua vigência, de 1964 a 1986, o BNH teve grande repercussão nacional, em especial, por beneficiar a classe média brasileira. Tal fato influenciou no aumento da desigualdade de renda no país e causou muitos conflitos ideológicos.

Após 22 anos, o BNH foi extinto e suas atividades transferidas para a Caixa Econômica Federal. Novamente, o objetivo de redução do déficit habitacional foi muito pouco atingido, assim como a redução de favelas e a melhoria de vida do cidadão brasileiro, em especial, os residentes de baixa renda em grandes cidades. 
De acordo com o Valadares (2017),

[...] apesar dos esforços, o governo chegou à conclusão de que os problemas enfrentados pelo $\mathrm{BNH}$ eram insolúveis; considerava-se que o banco não estava servindo como instrumento de desenvolvimento do setor e administrava um déficit, calculado para um período de 15 anos, de cerca de 20 bilhões de cruzados. Foram implementados incentivos para que os cerca de 3,5 milhões de mutuários existentes no país quitassem seus compromissos com o sistema antigo. O Decreto-Lei $\mathrm{n}^{\mathrm{o}} 2.291$, de 21 de dezembro de 1986, que extinguiu o $\mathrm{BNH}$, estabeleceu que as atividades do banco fossem absorvidas pela Caixa Econômica Federal, pelo Banco Nacional do Desenvolvimento Econômico e Social (BNDES) e pela Secretaria de Habitação do Ministério de Desenvolvimento Urbano (MDU). A secretaria do MDU ficou encarregada de administrar as aplicações de recursos na área de habitação de baixa renda; a Caixa Econômica e os bancos comerciais passaram a ser os agentes do crédito imobiliário; e o BNDES assumiu a responsabilidade pelos projetos de transporte urbano e saneamento básico, de natureza social. A normatização do SFH passou a ficar a critério do Conselho Monetário Nacional. Os 8.300 funcionários do BNH ficaram passíveis de serem aproveitados pelos órgãos que deram continuidade às atividades do banco, mas sem estabilidade de emprego, o que provocou várias manifestações de protesto contra a decisão oficial de extinguir o órgão.

$\mathrm{O} \mathrm{BNH}$ entrou para a história por ter sido um plano falho em quesito de planejamento e investimento público. Novamente, questões de interesse políticoprivado foram preponderantes frente aos problemas sociais brasileiros.

\subsubsection{Modelo de programa habitacional de âmbito municipal: Programa "Vila Viva"}

Um exemplo de pioneirismo de política habitacional de grande impacto foi criada em Belo Horizonte, em 1983, com intuito de tentar solucionar o problema da habitação, principalmente da legalização das áreas informais da cidade. Criou-se, assim, o PRÓ-FAVELA (Programa Municipal de Regularização de Favelas), considerado como "[...] a primeira ação pública que reconhecia a especificidade da favela e o direito de seus habitantes à moradia e aos bens e serviços básicos". (TONUCCI FILHO; ÁVILA, 2008, p. 14).

A partir deste programa e com a criação da URBEL (Companhia Urbanizadora de Belo Horizonte), órgão municipal responsável pela urbanização, regularização e titulação fundiária das favelas na cidade, Belo Horizonte tornou-se referência em todo o Brasil, contando então com o maior projeto de regularização de favelas em andamento no país, o Programa "Vila Viva". (TONUCCI FILHO; ÁVILA, 2008, p. 15).

De acordo com Duarte et al. (2009) o programa de urbanização de favelas "Vila Viva" começou a ser discutido em 1994, sendo o ano de 2000 o início efetivo ainda em forma de projeto piloto. Hoje ele é considerado referência em urbanização de favelas no 
Brasil, sendo que em Belo Horizonte já beneficiou sete vilas e aglomerados, sendo elas Vila Califórnia, Vila São José, Vila Pedreira Prado Lopes, Aglomerado Santa Lúcia, Conjunto Taquaril, Aglomerado da Serra e Aglomerado Morro das Pedras. O programa teve como objetivos modificar, melhorar e construir nos espaços beneficiados, e entre as obras estão sendo feitas as de infraestrutura, construções de novas habitações e áreas de lazer. Cerca de $\mathrm{R}$ \$ 572,3 milhões foram os recursos destinados às obras do programa, por intermédio do governo federal, através do Plano de Aceleração do Crescimento (PAC I), do financiamento da Caixa Econômica Federal (CEF) e do Banco Nacional do Desenvolvimento Social (BNDES), durante o período de 2005 e 2009. (DUARTE et al., 2009).

Duarte et al. (2009) mencionam que o Aglomerado da Serra foi para onde se destinou a maior parte dos recursos, $\mathrm{R} \$ 171,2$ milhões em investimentos. O aglomerado é constituído por seis vilas, sendo considerado o maior de Belo Horizonte, localizado na região centro-sul da cidade. O programa no Aglomerado da Serra tem a pretensão de melhorar as condições de vida dos moradores com a redução no índice de criminalidade, decorrente do tráfico de drogas, o acesso à infraestrutura básica de qualidade, melhorias nos sistemas de saúde e educação pública, dentre outras. O programa foi iniciado em 1998 com o desenvolvimento do Plano Global Específico (PGE), e nele a comunidade participa diretamente na sua elaboração com sugestões de obras prioritárias para melhoria de vida dos moradores. Sendo assim, com as obras iniciadas efetivamente no final de 2005, teve como pretensão que ao seu final, a prefeitura pudesse entregar um total de 360 unidades habitacionais para abrigar parte das famílias removidas. (DUARTE et al., 2009).

Dessa forma, o Programa "Vila Viva" se caracterizou por envolver as ações essenciais para que a regularização seja bem sucedida, sendo elas: legalização fundiária, urbanização e desenvolvimento socioeconômico.

\subsubsection{Modelo de programa habitacional de âmbito federal: Programa "Minha Casa Minha Vida" (PMCMV)}

O PMCMV foi criado em 2009 pela Medida Provisória no 459, de 25 de março de 2009, que dispõe sobre o Programa "Minha Casa, Minha Vida" - PMCMV (BRASIL, 2009a), e a regularização fundiária de assentamentos localizados em áreas urbanas que foi convertida na Lei $n^{\circ} 11.977$, de 7 de julho de 2009. (BRASIL, 2009b). 
Tanto a medida quanto a lei apresentam informações de cunho jurídico, não sendo possível identificar se houve ou não um planejamento prévio do PMCMV.

Devida à falta de maiores informações sobre o processo de criação do PMCMV, foram solicitadas maiores informações ao Sistema Eletrônico do Serviço de Informação ao Cidadão (e-SIC) (BRASIL, 2014b, 2014c), porém as respostas foram evasivas quanto à possibilidade de um planejamento anterior à implementação do PMCMV. Conforme respostas obtidas pelo e-SIC (BRASIL, 2014b), o PMCMV não foi um programa planejado, sendo possível identificar que suas causas foram de cunho políticomercadológica, pois, no período em questão, o sistema econômico mundial passava por uma forte crise, que advinha do setor imobiliário americano. Acreditamos que, numa tentativa de sanar os efeitos da crise externa, procurou-se elaborar um plano que pudesse impulsionar o mercado interno, ao mesmo tempo em que seria um instrumento de marketing partidário, observando novamente o período e o cenário políticoeconômico do país.

Novamente é válido ressaltar que o interesse deste trabalho não é apresentar questionamentos sobre a importância e originalidade do PMCMV pela ótica social que teve como objetivo sanar o déficit habitacional e possibilitar que indivíduos menos favorecidos economicamente pudessem adquirir sua casa própria, mas fazer uma crítica analítica sobre o seu planejamento e os resultados obtidos com o PMCMV e possíveis consequências em um futuro próximo para os planejamentos urbano e econômico relacionados às políticas habitacionais.

\subsubsection{Uma breve análise do Programa “Minha Casa Minha Vida" (PMCMV)}

Buscando sanar o problema de déficit habitacional e possibilitar uma melhoria de vida aos cidadãos brasileiros, o governo criou em 2009 o Programa "Minha Casa Minha Vida" (PMCMV). (BRASIL, 2009a, 2009b). De acordo com as informações disponibilizadas pelo Ministério do Planejamento, Orçamento e Gestão (BRASIL, 2014a), o PMCMV foi criado

\footnotetext{
Para promover o acesso à moradia digna a todos os brasileiros, direito social assegurado pela Constituição em seu artigo $6^{\circ}$, o Governo Federal potencializou os investimentos na política habitacional e diversificou seus instrumentos. Lançado em 2009, o Programa Minha Casa Minha Vida MCMV instituiu um modelo célere de provisão habitacional de interesse social, que combina a concessão de subsídios de acordo com a capacidade de pagamento das famílias, a indução da participação dos agentes privados e a cooperação federativa. (BRASIL, 2014a, p. 55, grifo nosso).
} 
O Ministério das Cidades (BRASIL, 2017a) defende que

O Minha Casa Minha Vida (MCMV) é a maior iniciativa de acesso à casa própria já criada no Brasil. O programa, que mudou a história da habitação do País, prevê diversas formas de atendimento às famílias que necessitam de moradia, considerando a localização do imóvel - na cidade e no campo renda familiar e valor da unidade habitacional. Além disso, o programa também contribui para a geração de emprego e renda para os trabalhadores da construção civil, que realizam as obras.

O PMCMV teve como meta inicial a construção de um milhão de habitações e a redução do déficit habitacional do país em 14\%, aferido no ano de 2007 em 7,2 milhões. (BRASIL, 2009c). O grande diferencial deste programa é oportunizar às famílias com renda de até três salários mínimos adquirir seu primeiro imóvel, assim como ampliar a possibilidade da aquisição de imóveis para as famílias com renda de até dez salários mínimos. (BRASIL, 2009c).

De acordo com a Lei $\mathrm{n}^{\mathrm{o}}$ 11.977, de 7 de julho de 2009,

Art. $1^{\circ} \mathrm{O}$ Programa Minha Casa, Minha Vida - PMCMV tem por finalidade criar mecanismos de incentivo à produção e aquisição de novas unidades habitacionais, requalificação de imóveis urbanos e produção ou reforma de habitações rurais, para famílias com renda mensal de até dez salários mínimos [...]. (BRASIL, 2009b).

Segundo informações do Ministério das Cidades (BRASIL, 2017a), o PMCMV é "um programa do governo federal que busca facilitar a conquista da casa própria para as famílias de baixa renda".

Na implementação do PMCMV II, em 2011, regido pela Lei no 12.424, de 16 de junho de 2011, a meta de construção de habitação dobrou para dois milhões de habitações. (BRASIL, 2011).

Segundo a Secretaria de Governo (BRASIL, 2017b, grifo do autor)

Em dezembro de 2014, o Minha Casa Minha Vida atingiu a meta proposta para o período 2011-2014, de contratar a construção de 2,75 milhões de moradias em 5.239 municípios, alcançando o desafio de prover moradia para essa parcela da população. Em menos de cinco anos, foi contratada a construção de 3,76 milhões de novas casas e apartamentos, grande parte destinada à população de baixa renda. Desde 2009, são mais de 3,76 milhões de moradias contratadas. Os investimentos desde 2009 ultrapassam o valor de R\$ 244,2 bilhões, dos quais quase 80\% foram contratados a partir de 2011.

O programa, na área urbana, é dividido por três faixas de renda mensal: até $\mathrm{R} \$ 1.600$ (faixa 1), até $\mathrm{R} \$ 3.100$ (faixa 2) e até $\mathrm{R} \$ 5$ mil (faixa 3). Na área rural, as faixas de renda são anuais: até $\mathrm{R} \$ 15$ mil (1), até $\mathrm{R} \$ 30$ mil (2) e até R\$ 60 mil (3). Além da construção de unidades habitacionais (Minha Casa Minha Vida), fazem parte desse eixo as áreas Sistema Brasileiro de Poupança e Empréstimo (SBPE) e Urbanização de Assentamentos Precários. 
Porém, vale ressaltar que

Até abril de 2014, o MCMV [...] contratou a execução de 3,4 milhões de moradias, totalizando valores de mais de $\mathbf{R} \$ 211$ bilhões, tendo sido entregues 1,7 milhão de unidades. Atendendo a famílias de baixa renda (renda mensal até R \$1.600), foram contratadas cerca de 1,7 milhão de unidades, das quais mais de 600 mil foram entregues, alcançando uma escala nacional de investimentos para a redução do déficit habitacional abrangência de cerca de $93 \%$ dos municípios brasileiros. (BRASIL, 2014a, p. 55-56, grifo nosso).

É possível constatar que o PMCMV tem gerado impactos positivos e produtivos para o país, principalmente por sua abrangência territorial, capacidade de estimular a geração de renda e empregos em diversos setores, coparticipação das três esferas governamentais - federal, estadual e municipal -, grande amplitude de beneficiários e expressivo valor estimado para serem investidos. Porém, é sempre válido questionar e verificar seus resultados, principalmente, por apresentar suspeitas de irregularidades e ineficiência em termos de bem-estar social para as famílias contempladas com o programa e na avaliação da gestão dos investimentos públicos alocados, pois,

\begin{abstract}
Apesar do esforço do governo em financiar a produção de elevado número de habitações populares por intermédio do PMCMV/FAR, [...] significativa quantidade de empreendimentos foi entregue apresentando diversas patologias construtivas relacionadas às fases de concepção e execução das obras. A maior parte das ocorrências relaciona-se a defeitos ou vícios construtivos; inadequações nas dimensões, instalações e materiais empregados na residência; indisponibilidade de equipamentos de lazer; e deficiências na pavimentação asfáltica, calçamento, drenagem urbana e sistema de esgoto sanitário ou pluvial. Também foram constatadas inadequações relativas à acessibilidade para pessoas com deficiência ou mobilidade reduzida. (TRIBUNAL DE CONTAS DA UNIÃO, 2013, p. 3).
\end{abstract}

As inadequações e problemas oriundos de construções com materiais inferiores e de baixa qualidade poderá gerar uma demanda futura, e mesmo no presente, com a recusa dos contratantes em aceitarem os imóveis e com perdas de valores monetários significativos para os governos, além de imóveis abandonados e de diminuição irreal do déficit público. Pesando as consequências, poderá haver uma nova demanda: desta vez por um investimento de custo maior, ficando comprovada a falta de efetividade da intervenção estatal quando se trata de programas habitacionais.

Sendo assim, uma análise econômica que se paute na aferição da efetividade dos investimentos públicos alocados no PMCMV, que objetive analisar a proposta de investimento do PMCMV, que compare os indicadores de crescimento e desenvolvimento econômico com os divulgados e almejados pelo Estado brasileiro 
durante o período de 2009 a 2014 e avalie se estes valores investidos foram realmente efetivos para o desenvolvimento regional e urbano das cidades contempladas com o PMCMV, fornecerá aos interessados em planejamento e políticas públicas uma revisão no seu modo de pensar e uma atualização quanto às ações que poderão realmente atrair mais benefício real para a sociedade, possibilitando

[...] que todos os empreendimentos habitacionais contratados sejam providos de equipamentos comunitários, comércio e serviços públicos; alcançar padrões satisfatórios de qualidade das obras executadas; tornar mais efetivas as ações do TTS no que tange à geração de trabalho e renda e à gestão condominial; atender, de forma eficaz e equitativa, as metas regionais de contratação. (TRIBUNAL DE CONTAS DA UNIÃO, 2013, p. 4).

Fica evidenciada a necessidade de repensar e de implementar ações governamentais que possibilitem um real desenvolvimento urbano e, assim, maior bemestar social, conforme nos mostra a auditoria do Tribunal de Contas da União (2013), sobre a efetividade do programa relacionada ao critério de desenvolvimento urbano, pois, foi verificado que o programa não tem mostrado efetividade no que

[...] diz respeito à produção de moradias em zonas urbanas não consolidadas e com entorno desprovido de escola, creche e unidade básica de saúde, falta de comércio local e de áreas de lazer e de recreação em suas proximidades. A questão da localização dos empreendimentos torna-se, desse modo, um ponto crítico do programa. Apesar de o programa definir como um dos critérios de priorização de atendimento a municípios a adoção de instrumentos de intervenção sobre o uso e ocupação de terras urbanas e de combate à retenção especulativa de terrenos vazios, na prática, não há concorrência entre os projetos apresentados. Dessa forma, o mecanismo concebido para induzir boas práticas no planejamento territorial dos municípios, acaba tendo pouco efeito prático. (TRIBUNAL DE CONTAS DA UNIÃO, 2013, p. 3-4, grifo nosso).

Ou seja, é possível identificar que, além das falhas na elaboração do PMCMV, existem, também, inúmeras falhas técnicas e econômicas que poderão ser refletidas na necessidade de novos recursos públicos para refazer aquilo que deveria ter sido realizado uma única vez.

No caso do Brasil, e em outros países com situações similares, os governos tendem a investir em setores que apresentam maior importância econômica, tecnológica e, por último, social. Os programas de cunho habitacional são tidos como fortes estimuladores de geração de emprego e renda, atrelados ao setor de infraestrutura que comporta investimentos em manutenção e construção de novas estradas, portos e infraestrutura urbana - ruas, praças e outros.

Para um melhor entendimento sobre o que foi o objetivo do PMCMV e o que foi o foco da auditoria do TCU, também objeto deste trabalho, apresentam-se a seguir o 
conceito de déficit habitacional - indicador orientador da criação do PMCMV - e quatro indicadores qualitativos utilizados para a avaliação de desempenho das intervenções estatais, a saber, economicidade, eficiência, eficácia e efetividade.

Segundo o Tribunal de Contas da União (2013),

O conceito de déficit habitacional compreende deficiências no estoque de moradias relacionadas às seguintes situações: a) habitações precárias (domicílios rústicos e improvisados); b) coabitação familiar (domicílios e cômodos alugados, cedidos e próprios em que há famílias conviventes secundárias); e c) domicílios alugados (ônus excessivo com aluguel e adensamento excessivo de moradores). (TRIBUNAL DE CONTAS DA UNIÃO, 2013, p. 103, grifo nosso).

Para o Tribunal de Contas da União (2013), os valores utilizados para a criação do PMCMV foram, baseados no

[...] estudo mais recente sobre o déficit habitacional no Brasil, produzido a partir de dados da Pesquisa Nacional por Amostra de Domicílios (Pnad), referentes a 2008, aponta que, naquele ano, o déficit habitacional estimado correspondia a 5,5 milhões de domicílios, dos quais 4,6 milhões $(83,5 \%)$ localizavam-se nas áreas urbanas. $\mathrm{O}$ déficit atinge com maior intensidade famílias com renda de até três salários mínimos $(89,6 \%)$, [...], situação esta predominante em todas as regiões brasileiras, sendo mais acentuada no Nordeste, com $95,6 \%$, e ligeiramente menor no Sul e Sudeste com $83,4 \%$ e 87,5\%, respectivamente. (MINISTÉRIO DAS CIDADES, 2011, p. 29, 37 apud TRIBUNAL DE CONTAS DA UNIÃO, 2013, p. 103, grifo nosso).

A seguir, na tabela 1, observamos discrepâncias entre as informações referentes ao número do déficit habitacional, publicadas pelo Ministério das Cidades (2011), e os dados da Câmara Brasileira da Indústria da Construção (2015), baseados no Instituto Brasileiro de Geografia e Estatística (IBGE), em especifico, na Pesquisa Nacional por Amostra de Domicílios (PNAD) 2007 - 2012. 
Tabela 1 - Déficit Habitacional Total, Relativo e por Componentes 2007 a 2012

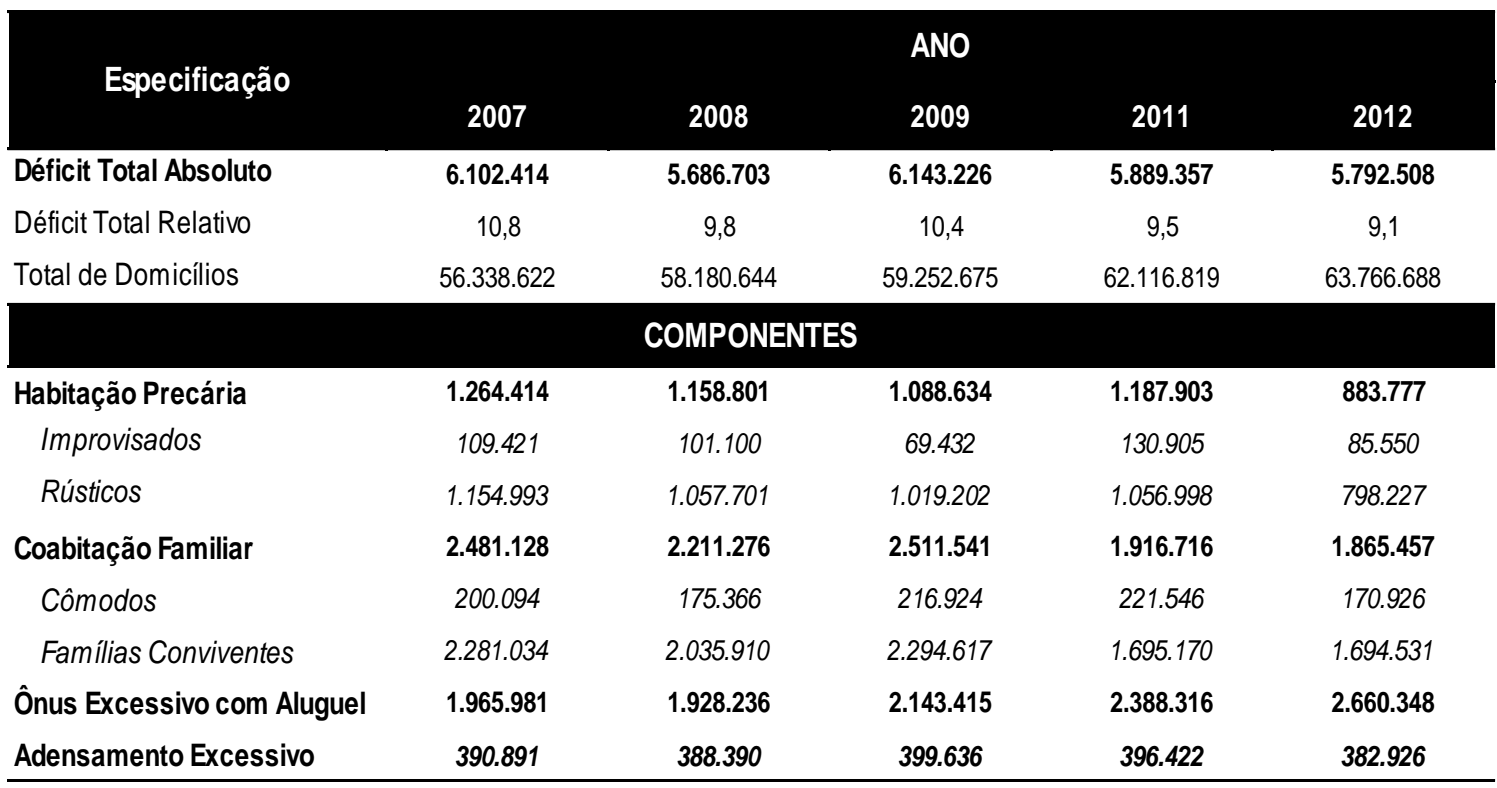

Fonte: Dados básicos: Instituto Brasileiro de Geografia e Estatística (IBGE), Pesquisa Nacional por Amostra de Domicílios (PNAD) 2007 - 2012 apud Câmara Brasileira da Indústria da Construção (2015).

Elaboração: Fundação João Pinheiro (FJP), Centro de Estatística e Informações (CEI).

Nota Técnica: Déficit Habitacional no Brasil Anos 2011 e 2012 / Fundação João Pinheiro.

Porém, como vimos acima, na tabela 1, o valor do déficit habitacional do Brasil estava acima de 6 milhões de domicílios no ano de 2007, como nos mostra a Câmara Brasileira da Indústria da Construção (2015), que apresenta os valores referentes ao déficit habitacional total, relativo e por componentes, do período de 2007 a 2012. Apesar da discrepância, é importante salientar que os valores por si só apresentam justificativas para implementação do PMCMV.

Após concluir a importância e relevância social do PMCMV, faz-se necessário compreender quatro indicadores qualitativos utilizados para a avaliação de desempenho das intervenções estatais. Segundo o Ministério do Planejamento, Orçamento e Gestão (2010), são utilizados quatro indicadores, a saber:

\footnotetext{
- Economicidade: medem os gastos envolvidos na obtenção dos insumos (materiais, humanos, financeiros etc.) necessários às ações que produzirão os resultados planejados. Visa a minimizar custos sem comprometer os padrões de qualidade estabelecidos e requer um sistema que estabeleça referenciais de comparação e negociação;

- Eficiência: essa medida possui estreita relação com produtividade, ou seja, o quanto se consegue produzir com os meios disponibilizados. Assim, a partir de um padrão ou referencial, a eficiência de um processo será tanto maior quanto mais produtos forem entregues com a mesma quantidade de insumos, ou os mesmos produtos e/ou serviços sejam obtidos com menor quantidade de recursos;
} 
- Eficácia: aponta o grau com que um Programa atinge as metas e objetivos planejados, ou seja, uma vez estabelecido o referencial (linha de base) e as metas a serem alcançadas, utiliza-se indicadores de resultado [...] para avaliar se estas foram atingidas ou superadas;

- Efetividade: mede os efeitos positivos ou negativos na realidade que sofreu a intervenção, ou seja, aponta se houve mudanças socioeconômicas, ambientais ou institucionais decorrentes dos resultados obtidos pela política, plano ou programa. (BRASIL, 2010, p. 31-32).

Dentre os indicadores qualitativos utilizados pela gestão pública é substancialmente relevante para este trabalho o indicador de efetividade. Observa-se que a efetividade diz respeito aos efeitos oriundos do PMCMV na vida dos indivíduos beneficiários e às possíveis mudanças ocorridas nas cidades contempladas com $\mathrm{o}$ programa.

Sendo assim, foi possível constatar a ausência da efetividade do PMCMV, principalmente, no critério de mudanças socioeconômicas, pois não foram detectadas melhorias urbanas para as famílias beneficiárias, uma vez que ficou constatado que muitas famílias tiveram suas residências alocadas em territórios distantes dos grandes centros e dos seus trabalhos, além de ter sido observado que os aspectos ambientais não foram respeitados, indiciando não-efetividade do PMCMV. Entretanto, verifica-se que uma pequena parcela dos beneficiários do PMCMV obteve êxitos nos resultados.

É importante relatar que a economicidade e a eficiência do PMCMV não foram atingidas devido à utilização de materiais de baixa qualidade e de baixo custo para as empresas de construção civil, refletindo diretamente no cotidiano das famílias beneficiadas com o programa, causando-lhes danos físicos e psicológicos. Estas tiveram que conviver com defeitos físicos - instalações erradas, falta de qualidade e segurança nos imóveis. No relatório de auditoria do Tribunal de Contas da União (2013), relata-se que foram encontradas "instalação de esquadrias de portas e janelas com material de baixa qualidade e com fixação deficiente, o que torna as casas vulneráveis a arrombamentos”. (TRIBUNAL DE CONTAS DA UNIÃO, 2013, p. 32), comprovando a ineficiência do PMCMV.

A partir dos resultados deste estudo e da compreensão da importância do planejamento urbano em um programa de cunho habitacional, conclui-se que, apesar do histórico político habitacional, o Brasil continua a produzir os mesmos erros - ofertar programas e subsídios sem um planejamento estruturado, sem que as intervenções estatais tenham vínculo com agentes e entidades brasileiras que aportariam maior 
efetividade para as propostas governamentais e elevaria os níveis de crescimento e desenvolvimento econômico, social e ambiental do país.

\section{Considerações finais}

Este trabalho realizou uma breve análise bibliográfica e documental sobre a intervenção do estado no atual programa nacional de habitação - Programa "Minha Casa Minha Vida" (PMCMV). Para isso, priorizou-se o período de 2009 a 2014, focalizando as ações destinadas a famílias com até três salários mínimos.

Foi constatado que o PMCMV apresenta significante valor mercadológico, pois foi implementado em um setor de grande importância para a geração de renda e emprego, porém os resultados alcançados com o programa em relação ao desenvolvimento urbano e regional não são satisfatórios, pois não apresentam simetria com o bem-estar social dos beneficiários e nem com aspectos ambientais.

A falta de efetividade dos resultados alcançados pelo PMCMV, em específico, as ações destinadas a famílias com até três salários mínimos, comprova que as falhas na elaboração e implementação do PMCMV, no que tange a aspectos urbanistas indispensáveis para a construção eficaz da cidade, sem novos ambientes à margem, evidenciam a necessidade de repensar a prática de elaboração de planejamento urbano e/ou econômico em curto prazo e a implementação de programas governamentais de grande expressividade. Verificou-se que estes programas são, geralmente, planejados inadequadamente, prejudicando a efetividade dos resultados e gerando mais prejuízo econômico para o país, com aumento de problemas sociais como desigualdade de renda e o próprio déficit habitacional, que continua a crescer apesar dos programas habitacionais já implementados.

Ressaltamos que este trabalho tratou o PMCMV pela ótica do planejamento urbano e da efetividade da intervenção estatal. Sendo assim, acreditamos que há muito a ser feito para inserirmos uma cultura de planejamento e ética relacionada à condução das políticas públicas, em especial, as políticas sociais e econômicas, ficando este como um trabalho introdutório para uma mudança na prática de nossos gestores públicos e, quiçá, para contribuição econômica do futuro urbano do Brasil. 


\section{REFERÊNCIAS}

BONDUKI, Nabil Georges. Origens da habitação no Brasil. Análise Social, Lisboa, v. 29, n. 127, p. 711-732, 1994. Disponível em:

<http://analisesocial.ics.ul.pt/documentos/1223377539C9uKS3pp5Cc74XT8.pdf > Acesso em: 08 jan. 2017.

BRASIL. Câmara dos Deputados. Decreto- Lei $n^{\circ}$ 9.218, de $1^{\circ}$ de Maio de 1946, que autoriza a instituição da "Fundação da Casa Popular". Diário Oficial da União, Rio de Janeiro, Seção 1, de 04 de maio de 1946, p. 6679. Disponível em:

<http://www2.camara.leg.br/legin/fed/declei/1940-1949/decreto-lei-9218-1-maio-1946417087-publicacaooriginal-1-pe.html>. Acesso em: 07 fev. 2017.

BRASIL. Ministério das Cidades. Cidade para todos: construindo uma política democrática e integrada para as Cidades. 2003. Disponível em:

<http://www.ipea.gov.br/participacao/images/pdfs/conferencias/Cidades/texto_base_1_ conferencia_cidades.pdf $>$. Acesso em: 24 dez. 2016.

BRASIL. Medida provisória no 459, de 25 de março de 2009, que dispõe sobre o Programa Minha Casa, Minha Vida - PMCMV, a regularização fundiária de assentamentos localizados em áreas urbanas, e dá outras providências. Diário Oficial da União, Brasília, Seção 1, de 26 de março de 2009a, p. 1. Disponível em: <http://www.planalto.gov.br/ccivil_03/_ato2007-2010/2009/mpv/459.htm>. Acesso em: 07 fev. 2017.

BRASIL. Lei n ${ }^{\circ} 11.977$, de 7 de julho de 2009, que dispõe sobre o Programa Minha Casa, Minha Vida - PMCMV e a regularização fundiária de assentamentos localizados em áreas urbanas; altera o Decreto-Lei no 3.365, de 21 de junho de 1941, as Leis nos 4.380, de 21 de agosto de 1964, 6.015, de 31 de dezembro de 1973, 8.036, de 11 de maio de 1990, e 10.257, de 10 de julho de 2001, e a Medida Provisória no 2.197-43, de 24 de agosto de 2001; e dá outras providências. Diário Oficial da União, Brasília, Seção 1, de 08 de julho de 2009b, p. 2. Disponível em: <http://www.planalto.gov.br/ccivil_03/_ato2007-2010/2009/lei/111977.htm>. Acesso em: 07 fev. 2017.

BRASIL. Ministério das Cidades. Minha Casa, Minha Vida: 1 milhão de casas, crédito, emprego, benefícios e esperança para os brasileiros. 2009c. Disponível em: <http://www.pbqp-h.com.br/arquivos/download/Cartilha_Mcmv.pdf >. Acesso em: 10 jan. 2017.

BRASIL. Ministério do Planejamento, Orçamento e Gestão. Secretaria de Planejamento e Investimentos Estratégicos (SPI). Indicadores de programas: Guia Metodológico. Brasília: Ministério do Planejamento, Orçamento e Gestão; Secretaria de Planejamento e Investimentos Estratégicos, 2010. Disponível em:

<http://www.planejamento.gov.br/secretarias/upload/Arquivos/spi/publicacoes/100316_ 
indicadores_programas-guia_metodologico.pdf>. Acesso em: 24 dez. 2016.

BRASIL. Lei $n^{\circ} 12.424$, de 16 de junho de 2011, que altera a Lei no 11.977 , de 7 de julho de 2009, que dispõe sobre o Programa Minha Casa, Minha Vida - PMCMV e a regularização fundiária de assentamentos localizados em áreas urbanas, as Leis nos 10.188, de 12 de fevereiro de 2001, 6.015, de 31 de dezembro de 1973, 6.766, de 19 de dezembro de 1979, 4.591, de 16 de dezembro de 1964, 8.212, de 24 de julho de 1991, e 10.406, de 10 de janeiro de 2002 - Código Civil; revoga dispositivos da Medida Provisória no 2.197-43, de 24 de agosto de 2001; e dá outras providências. Diário Oficial da União, Brasília, Seção 1, de 17 de junho de 2011, p. 2. Disponível em: <http://www.planalto.gov.br/ccivil_03/_Ato2011-2014/2011/Lei/L12424.htm\#art1>. Acesso em: 07 fev. 2017.

BRASIL. Ministério do Planejamento, Orçamento e Gestão. Caderno de monitoramento do PPA 2012-2015: retrato das políticas sociais na PNAD 2012. Brasília: Ministério do Planejamento, Orçamento e Gestão, jun. 2014a. Disponível em: $<$ http://www.planejamento.gov.br/secretarias/upload/arquivo/spi-1/ppa1/publicacoes/140707_cad_monit_ppa-pnad-1.pdf>. Acesso em: 10 fev. 2017.

BRASIL. Sistema Eletrônico do Serviço de Informação ao Cidadão (e-SIC). Pedido de acesso à informação. Protocolo de informação 80200000622201424 . Ministério das Cidades. Resposta 622. Disponível em:

$<$ http://www.acessoainformacao.gov.br/sistema/Pedido/DetalhePedido.aspx?id=S2qRoj pErNw=>. Acesso em: 15 out. 2014 b.

BRASIL. Sistema Eletrônico do Serviço de Informação ao Cidadão (e-SIC). Pedido de acesso à informação. Protocolo de informação 03950001965201482. Ministério das Cidades. Resumo PMCMV: Brasil. Disponível em: < http://www.acessoainformacao.gov.br/sistema/Pedido/DetalhePedido.aspx?id=ka4OsK/ zDyg=>. Acesso em: 15 out. 2014c.

BRASIL. Ministério do Planejamento, Orçamento e Gestão. Secretaria de Planejamento e Investimentos Estratégicos. Plano Plurianual 2016-2019: desenvolvimento, produtividade e inclusão social - Mensagem Presidencial. 2015. Disponível em: <http://www.planejamento.gov.br/secretarias/upload/arquivo/spi-1/ppa-2016-2019/ppa2016-2019-ascom-3.pdf>. Acesso em: 09 fev. 2017.

BRASIL. Ministério das Cidades. Habitação. Portal Minha Casa Minha Vida. Saiba mais sobre o programa. Saiba mais sobre o Minha Casa Minha Vida.Disponível em: <http://www.minhacasaminhavida.gov.br/index.html>. Acesso em: 10 fev. 2017a.

BRASIL. Secretaria de Governo. Notícias. Minha Casa Minha Vida. Disponível em: $<$ http://www.secretariadegoverno.gov.br/iniciativas/internacional/fsm/eixos/inclusaosocial/minha-casa-minha-vida>. Acesso em: 13 fev. $2017 \mathrm{~b}$.

CÂMARA BRASILEIRA DA INDÚSTRIA DA CONSTRUÇÃO. Banco de dados. 
Disponível em: <http://www.cbicdados.com.br/home/>. Acesso em: 03 maio 2015.

CLEMENTINO, Maria do Livramento Miranda. Ordenamento e planejamento territorial: a falta que faz o plano metropolitano. In: COLOQUIO INTERNACIONAL DE GEOCRÍTICA, 10, 2008, Barcelona. Diez años de cambios en el mundo, en la geografía y en las ciencias sociales: 1999-2008: anais. Barcelona: Universidad de Barcelona, 2008. Disponível em: <http://www.ub.edu/geocrit/-xcol/252.htm>. Acesso em: 10 jan. 2017.

DUARTE, Camila et al. A Valorização do Espaço: Um Estudo do Vila Viva, Projeto de Urbanização de Vilas e Favelas em Belo Horizonte. In: ENCUENTRO DE GEÓGRAFOS DA AMÉRICA LATINA, 12., 2009, Montevidéu, Uruguai. Caminando en una América Latina en transformación: anais, 2009. p.1-9. Disponível em: $<$ http://observatoriogeograficoamericalatina.org.mx/egal12/Geografiasocioeconomica/G eografiaurbana/37.pdf>. Acesso em: 07 fev. 2017.

GOMES, Gláucia Carvalho. O projeto de "urbanização" Vila Viva e a valorização do valor na reprodução social do espaço de Belo Horizonte. In: ENCUENTRO DE GEÓGRAFOS DA AMÉRICA LATINA, 12, 2009, Montevidéu, Uruguai. Caminando en una América Latina en transformación: anais, 2009. p. 1-14. Disponível em: $<$ http://www.observatoriogeograficoamericalatina.org.mx/egal12/Geografiasocioecono mica/Geografiaurbana/75.pdf >. Acesso em: 07 jan. 2017.

MEDRADO, Maria José Celestino. Guia básico sobre normalização de trabalhos acadêmicos. Elaboração Maria José Celestino Medrado; colaboração e revisão Janaína Zaidan Bicalho Fonseca. Belo Horizonte: Edição do Autor, 2013. 54 p. Disponível em: $<$ https://drive.google.com/file/d/0B--KFYh4gGDIUHlsVU9SSXZzeDg/view>. Acesso em: 07 fev. 2017.

MEDRADO, Maria José Celestino. O impacto da ausência de planejamento urbano em programa habitacional brasileiro: uma contribuição econômica para o futuro urbano no Brasil. Palhoças: Universidade do Sul de Santa Catarina, 2015. p.13.

PIMENTA, Denise Aparecida O. et al. Programa Vila Viva: Contradições e resistências no processo de urbanização de uma favela em Belo Horizonte. In: ENCONTRO NACIONAL DA ASSOCIAÇÃO BRASILEIRA DE PSICOLOGIA SOCIAL, 15, 2009, Maceió. Psicologia Social e políticas de existência: fronteiras e conflitos: anais. Maceió: ABRAPSO, 2009. p. 1-9. Disponível em:

$<$ http://abrapso.org.br/siteprincipal/images/Anais_XVENABRAPSO/405.\%20programa \%20vila\%20viva.pdf $>$. Acesso em: 24 dez. 2016.

TONUCCI FILHO, João Bosco Moura; ÁVILA, Jorge Luís Teixeira. Urbanização da pobreza e regularização de favelas em Belo Horizonte. In: SEMINÁRIO SOBRE A ECONOMIA MINEIRA, 13, 2008, Diamantina. Anais... Diamantina: UFMG/Cedeplar, 2008. 21 p. Disponível em:

<http://www.cedeplar.ufmg.br/seminarios/seminario_diamantina/2008/D08A117.pdf>. Acesso em: 24 dez. 2016. 
TRIBUNAL DE CONTAS DA UNIÃO. Secretaria-Geral de Controle Externo. Secretaria de Métodos Aplicados e Suporte à Auditoria. Relatório de auditória:

Programa Minha Casa, Minha Vida. Brasília: Tribunal de Contas da União, out. 2013. Disponível em:

<http://portal.tcu.gov.br/lumis/portal/file/fileDownload.jsp?inline=1\&fileId=8A8182A1 4D92792C014D92858CFD7429>. Acesso em: 27 dez. 2016.

VALADARES, Lícia do Prado. Banco Nacional da Habitação (BNH). Atualização de Andrea Ribeiro Hoffmann. Disponível em:

$<$ http://www.fgv.br/cpdoc/acervo/dicionarios/verbete-tematico/banco-nacional-dahabitacao-bnh>. Acesso em: 07 fev. 2017. 